\title{
Influence of Saccharomyces cerevisiae fermentation products, SmartCare in milk replacer and Original XPC in calf starter, on the performance and health of preweaned Holstein calves challenged with Salmonella enterica serotype Typhimurium ${ }^{1}$
}

\author{
T. L. Harris, ${ }^{*}$ Y. Liang, ${ }^{*}$ K. P. Sharon, ${ }^{\star} †$ M. D. Sellers, ${ }^{*}$ I. Yoon, $\ddagger$ M. F. Scott, $\ddagger$ J. A. Carroll, $†$ and M. A. Ballou* ${ }^{* 2}$ \\ *Department of Animal and Food Sciences, Texas Tech University, Lubbock 79409 \\ †USDA-Agricultural Research Service Livestock Issues Research Unit, Lubbock, TX 79401 \\ ‡Diamond V Mills Inc., Cedar Rapids, IA 52404
}

\section{ABSTRACT}

This study was designed to investigate the effects of supplementing SmartCare (SC; Diamond V, Cedar Rapids, IA) in milk replacer and Original XPC (XPC; Diamond V) in calf starter on performance and health of preweaned calves following an oral challenge with Salmonella enterica. The study was performed in two 35 -d periods with 30 Holstein bull calves $(2 \pm 1 \mathrm{~d}$ of age) per period. In each period, calves were blocked by location in the barn and randomly assigned to treatments that included control, base milk replacer and calf starter with no added Saccharomyces cerevisiae fermentation products; SC, milk replacer with $1 \mathrm{~g}$ of $\mathrm{SC} /$ calf per day and base calf starter; and SC+XPC, milk replacer with $1 \mathrm{~g}$ of SC/calf per day and calf starter with $0.5 \%$ XPC on a dry matter basis. Calves were fed 350 $\mathrm{g}$ of milk replacer solids at $14 \%$ dry matter twice daily at 0700 and $1700 \mathrm{~h}$. Calf starter and water were offered ad libitum and intakes were recorded daily. Calves were challenged with $108 \mathrm{cfu}$ of sulfamethazine-resistant Salmonella enterica serotype Typhimurium orally on d 14 of the study. Fecal Salmonella shedding was determined on d 14 to 21 (daily), 24, 28, and 35 using selective media. Blood samples were collected on d $0,7,14,16$, 18, 21, 24, 28, and 35 and analyzed for hematology; plasma were analyzed for haptoglobin concentrations. All data were reported as $\mathrm{CON}, \mathrm{SC}$, and $\mathrm{SC}+\mathrm{XPC}$, respectively. Calf starter intake was increased from d 22 to 35 among $\mathrm{SC}+\mathrm{XPC}$ calves and from d 29 to 35 among SC calves. The SC+XPC calves had a lower neutrophil-to-lymphocyte ratio $(0.81,0.83$, and $0.69 \pm$ 0.051 ) throughout the study. The $\mathrm{SC}+\mathrm{XPC}$ calves also

\footnotetext{
Received December 22, 2016.

Accepted May 2, 2017.

${ }^{1}$ Mention of trade names or commercial products in this article is solely for the purpose of providing specific information and does not imply recommendation or endorsement by the USDA.

${ }^{2}$ Corresponding author: michael.ballou@ttu.edu
}

had lower hematocrits $(35.1,35.3$, and $33.4 \pm 0.54 \%)$ and hemoglobin concentrations $(10.8,10.6$, and $10.1 \pm$ $0.16 \mathrm{mg} / \mathrm{dL}$ ) throughout the study. We found a tendency for calves fed SC and SC+XPC to have more solid fecal scores during the week after the challenge. We observed no treatment or treatment $\times$ time differences on plasma haptoglobin concentrations (63, 48, and $60 \pm 0.5 \mu \mathrm{g} / \mathrm{mL})$. No treatment differences were observed in the fecal shedding of the Salmonella; however, we noted a tendency for a treatment difference in the percentage of calves positive for Salmonella present in the ileal tissue at d 21 after the challenge $(25,50$, and $60 \%$ ). Supplementing preweaned Holstein calves with both SC in milk replacer and XPC in calf starter improved starter intake and improved fecal consistency immediately after a mild Salmonella enterica challenge, but more data are needed to further understand how these yeast fermentation products influence the immune responses to Salmonella enterica.

Key words: calf, health, yeast fermentation product

\section{INTRODUCTION}

Enteric disease continues to account for a large proportion of morbidity and mortality among dairy calves in the first few weeks of life. According to the USDA National Animal Health and Monitoring System (NAHMS, 2002, 2007), from $48 \mathrm{~h}$ of life until weaning, the mortality rate of dairy calves is between 7.8 and $10.8 \%$. Salmonella is one of the major enteric pathogens that can cause severe local and systemic disease with a high risk of mortality, especially among young calves. Further, Salmonella is a zoonotic disease that poses both food safety and labor safety risks. Therefore, reducing colonization and shedding of enteric pathogens, such as Salmonella, would improve calf health and reduce the risk of disease in humans.

Major concern exists with the use of metaphylactic antibiotics in livestock, which is driving an interest in 
finding alternatives to antibiotic use. Nutrition is an attractive approach to reduce the risk of enteric disease, because nutrients or biologically active compounds can be delivered directly to the sites of infection and disease. Fermentation products, specifically derived from Saccharomyces cerevisiae were reported to improve enteric health and increase leukocyte function (Jensen et al., 2008; Magalhães et al., 2008; Brewer et al., 2014). SmartCare (SC; Diamond V, Cedar Rapids, IA) and XPC (XPC; Diamond V) are Saccharomyces cerevisiae fermentation products that can be supplemented to calf diets via milk (or milk replacer) and starter grains, respectively.

The objectives of the current study were to determine the effects of SC added in milk replacer and XPC added in the calf starter on performance characteristics, clinical signs of disease (diarrhea, fever, hematology), and gastrointestinal development of preweaned Holstein calves before and after they were experimentally challenged with Salmonella enterica serovar Typhimurium. It was hypothesized that $\mathrm{SC}$ and XPC would minimize performance losses, attenuate the severity of clinical signs, and improve rumen development in Holstein calves during salmonellosis.

\section{MATERIALS AND METHODS}

\section{Study Design}

The study was reviewed and approved the Animal Care and Use Committee of the Livestock Issues Research Unit of the USDA-Agricultural Research Service (ARS) in Lubbock, Texas. The study was conducted as a complete randomized block design study. The study consisted of 2 periods of $35 \mathrm{~d}$ each with 30 Holstein bull calves in each period. Calves were blocked by location in the barn and randomly assigned to 1 of 3 dietary treatments. Treatments included (1) control, base milk replacer and calf starter alone; (2) SmartCare (SC), base milk replacer $+1 \mathrm{~g} /$ calf per day of SmartCare added to the milk replacer and base calf starter; and (3) SmartCare + XPC (SC+XPC), base milk replacer $+1 \mathrm{~g} /$ calf per day of SmartCare added to the milk replacer and XPC included in the base calf starter at $0.5 \%$.

All calves were housed at the USDA-ARS Livestock Issues Research Unit enclosed calf barn and enrolled in the study at $2 \pm 1 \mathrm{~d}$ of age. At enrollment, BW of calves were recorded. In addition, peripheral blood samples were collected from each calf and total serum protein was immediately measured using a refractometer to estimate passive immunity status. To ensure adequate randomization, no differences among treatments in initial BW and total serum protein were confirmed immediately after enrollment in each period.

Calves were challenged orally with 108 stationarygrowth colony forming units of Salmonella enterica serotype Typhimurium strain SL1344. The Salmonella challenge was administered in the morning feeding on d 14 of the study and was administered in the calves' milk replacer. Ten milliliters of a $20 \%$ sodium bicarbonate and $20 \%$ calcium carbonate buffer was also added in the milk replacer to aid in buffering the $\mathrm{pH}$ of the abomasum to increase the survival of the Salmonella to the lower gastrointestinal tract. This strain of Salmonella is sulfamethazine-resistant, which was used to determine fecal shedding and tissue colonization of the bacteria after challenge. The observation period continued until $35 \mathrm{~d}$ after enrollment.

\section{Calf Selection and Housing}

All calves were received from 1 large commercial dairy located approximately $8 \mathrm{~km}$ east of Plainview, Texas. Only healthy calves that were provided $4 \mathrm{~L}$ of pooled colostrum via an esophageal tube within $6 \mathrm{~h}$ of birth were picked up from the dairy. The calves were transported from the dairy to the research facility each morning within $24 \mathrm{~h}$ of birth.

Calves were housed in the USDA-ARS livestock issues research unit calf research facility located approximately $25 \mathrm{~km}$ northwest of Lubbock, Texas. The facility is a Biosafety Level II Calf Research Facility that is an indoor, temperature-controlled environment. Calves were housed individually in pens $(1.2 \times 1.1 \mathrm{~m}$, width $\times$ length; Agri-Plastics, Tonawanda, NY). No bedding was provided in the pens, and the floor of the pens was calf mesh Tenderfoot and was raised above a manure pit.

\section{Animal Feeding and Care}

Calves were offered a milk replacer with no feed additives twice daily throughout the study at 0700 and 1700 h. The milk replacer consisted of $22 \% \mathrm{CP}$ and $20 \%$ fat (Land O Lakes, Minneapolis, MN; Table 1) and was fed at a rate of $350 \mathrm{~g}$ of milk solids per feeding and $14 \%$ solids. The milk replacer was offered at 38 to 41 oC. All milk replacer was fed using nipple bottles and any milk refusals were measured 15 min after the milk was offered.

Calf starter and water were also offered to calves beginning on $\mathrm{d} 1$ of the study in separate removable plastic buckets. Calf starter was mixed weekly and stored at the calf facility. The ingredient and formulated nutrient composition of the calf starter are reported 
in Table 1. Calf starter refusals were measured daily at $0730 \mathrm{~h}$ and the amount offered was adjusted daily for an approximate 15\% refusal. Water measurements were taken at the same time as calf starter intake and were determined by measuring the quantity of water remaining in the bucket using a ruler measuring to the nearest $0.5 \mathrm{~cm}$. Fresh water was then added to fill each bucket. Data were converted to milliliters before statistical analysis.

Visual exams of each calf were recorded at each feeding, which included a fecal score $(1=$ well-formed, not hard; $2=$ soft, pudding-like; $3=$ loose, pancake batterlike; or $4=$ watery, pulpy, orange juice-like). Rectal temperatures were collected each morning from 0600 to $0700 \mathrm{~h}$ from each calf on 14 to 21 (daily), 24, 28, and $35 \mathrm{~d}$ after enrollment using a hand-held thermometer (GLA Agricultural Electronics, San Luis Obispo, CA). Accuracy of the thermometer was confirmed before each period by placing the thermometer in a water bath at various known temperatures between 38 and $41^{\circ} \mathrm{C}$.

\section{Sample Collection and Analysis}

Performance Data. Calf starter intake was recorded daily. Individual BW were recorded at enrollment and at 14, 21, and $35 \mathrm{~d}$ after enrollment (Calf Cart Scale, Digi-Star, Fort Atkinson, WI). Calves were weighed at $0600 \mathrm{~h}$. Total DMI was calculated as milk replacer intake plus calf starter intake. Feed efficiency was calculated as the feed-to-gain ratio for each time interval between BW measurements.

Blood Samples. A peripheral blood sample $(12 \mathrm{~mL}$; $9 \mathrm{~mL}$ in heparinized and $3 \mathrm{~mL}$ in EDTA Vacutainers, Becton Dickinson, Franklin Lakes, NJ) was collected from the jugular vein of each calf at enrollment and at $7,14,16,18,21,24,28$, and $35 \mathrm{~d}$ after enrollment. Blood samples were obtained before the morning milk replacer feeding. Whole blood was analyzed for hema-

Table 1. The formulated nutrient contents of the milk replacer and calf starter

\begin{tabular}{lcc}
\hline Nutrient & Milk replacer & Calf starter \\
\hline DM, \% & 97 & 93 \\
CP, \% & 22 & 20 \\
Ether extract, \% & 20 & 4.8 \\
ADF (maximum), \% & 0.15 & 9 \\
ME, Mcal $/ \mathrm{kg}^{2}$ & 4.65 & 3.1 \\
Calcium, \% & 0.75 & 0.86 \\
Phosphorus, \% & 0.7 & 0.42 \\
Vitamin A (minimum), IU $/ \mathrm{kg}$ & 44,000 & 44,000 \\
Vitamin $\mathrm{D}_{3}$ (minimum), IU $/ \mathrm{kg}$ & 11,000 & 11,000 \\
Vitamin E (minimum), IU $/ \mathrm{kg}$ & 220 & 330 \\
\hline
\end{tabular}

tology, including hematocrit, total leukocyte counts, total neutrophil counts, total monocyte counts, total lymphocyte counts, ratio of neutrophils to lymphocytes, and hemoglobin using an Idexx Procyte Analyzer (Idexx Laboratories, Westbrook, ME) with bovinespecific algorithms. Plasma was collected and stored at $-80^{\circ} \mathrm{C}$ from the heparinized Vacutainer following centrifugation at $1,500 \times \mathrm{g}$ for $15 \mathrm{~min}$ at $4^{\circ} \mathrm{C}$. Plasma haptoglobin was quantified as described by Makimura and Suzuki (1982). A pooled plasma sample was used to calculate intra- and interassay coefficients of variation of 1.8 and $4.2 \%$, respectively, for the haptoglobin assay. The colorimetric data were quantified using a SpectraMax 340PC (Molecular Devices, Sunnyvale, CA). Plasma samples with known concentrations of haptoglobin were used to create a standard curve.

Fecal Samples. Fresh fecal samples were collected via digital stimulation from each calf on 7,15 to 21 (daily), 24, 28, and $35 \mathrm{~d}$ after enrollment. At each time point, $1 \mathrm{~g}$ of feces from each sample was weighed and serially diluted in sterile PBS (7.4 pH) before spread plating $100 \mu \mathrm{L}$ of diluted fecal sample in PBS on selective media [XLD agar (Himedia, Mumbai, India), sulfamethazine included at $512 \mathrm{mg} / \mathrm{L}$ of agar (Acros Organics, Thermo Fisher Scientific, Waltham, MA) contained in petri dishes. The plated petri dishes were then incubated at $37^{\circ} \mathrm{C}$ for $24 \mathrm{~h}$. After incubation, the dishes were then removed from the incubator and set on the laboratory bench for an additional $24 \mathrm{~h}$. This step aided in differentiation of selected Salmonella colonies from other bacterial populations that were sulfamethazine-resistant. After the 2-h laboratory bench incubation, the Salmonella colonies were then counted as the colonies with a black center and recorded to determine shedding of Salmonella in colony forming units per gram of wet fecal material.

Tissue Samples. After the 35-d observation period was completed, calves were euthanized and multiple samples were taken immediately postmortem. Major organs were removed and weighed, including the reticulorumen, omasum, abomasum, total intestines, liver, spleen, and kidneys. The reticulorumen, omasum, and abomasum were rinsed and cleaned of any residual ingesta before being weighed, whereas the intestines were weighed with the ingesta. The liver, spleen, and kidneys were trimmed of excess non-organ-specific tissue (fat and omentum) before being weighed. Tissue samples of the rumen, duodenum, and ileum were removed, rinsed gently with sterile $1 \times$ PBS, and preserved in formalin. These tissues were then sent to the Texas Tech Health Sciences Center pathology laboratory for slide preparation and hematoxylin and eosin staining; thus, tissue morphology could be analyzed under light microscopy. 
Ileal fluid, as well as tissue samples from the ileum and a mesenteric lymph node (MLN) were analyzed for the presence of the challenge Salmonella enterica. Ileal fluid was collected by making an incision in the ileum, approximately $10 \mathrm{~cm}$ anterior to the ileo-cecal junction, and aseptically transferring approximately 7 $\mathrm{mL}$ of fluid from the lumen of the ileum into a sterile $15-\mathrm{mL}$ conical tube. After the ileal fluid was transferred, the ileal tissue was gently rinsed with sterile $1 \times$ PBS, cut into 2 pieces, and stored either in sterile PBS or $10 \%$ formalin. The third MLN from the ileo-cecal junction was collected and stored in a sterile $15-\mathrm{mL}$ conical tube. One milliliters of ileal fluid was diluted in $10 \mathrm{~mL}$ of sterile PBS and $1 \mathrm{~g}$ of ileum tissue and MLN were then homogenized with a tissue homogenizer in 10 $\mathrm{mL}$ of sterile PBS for $30 \mathrm{~s}$. Subsequently, each respective sample was plated on XLD agar with $512 \mathrm{mg} / \mathrm{L}$ of sulfamethazine and incubated for $24 \mathrm{~h}$ at $37^{\circ} \mathrm{C}$. After 24 $\mathrm{h}$ of incubation at $37^{\circ} \mathrm{C}$, the petri dishes were removed from the incubator and allowed to incubate at room temperature on a laboratory bench. Once the dishes incubated for an additional $24 \mathrm{~h}$ at room temperature, the presence of Salmonella colonies were identified as a colony with a black center on each plate.

\section{Statistical Analysis}

Prior to any statistical interpretation, the residuals of all continuously distributed data were analyzed using the Univariate procedure of SAS to evaluate suitability of the data for parametric data analysis (SAS ver. 9.2, SAS Institute Inc., Cary, NC). All continuous, repeatedly measured data were analyzed as a repeated measure using the Mixed Procedure of SAS (ver. 9.2). The model included the fixed effects of treatment, time, and the interaction of treatment $\times$ time. Period and block were included as random effects. The subject of the repeated statement was calf nested within treatment, and the appropriate covariance structure for the within-calf measurement was chosen based on the lowest Bayesian information criterion. Initial BW was used as a covariate. A survival analysis was performed on the proportion of calves shedding the challenge Salmonella enterica strain in feces using the LifeTest procedure of SAS (ver. 9.2). The percentages of calves positive for the challenge Salmonella enterica strain in ileal tissue or MLN and average fecal score were analyzed using a Chi-squared test in the Freq procedure of SAS (ver. 9.2). Pairwise differences were performed for each statistical analysis to further evaluate treatment differences. Differences of $P \leq 0.05$ were considered significant and $0.05<P \leq 0.10$ was considered a tendency.

\section{RESULTS}

\section{Calf Losses}

Two calves died during the second period. One $\mathrm{SC}+\mathrm{XPC}$ calf died immediately after consuming milk replacer in the afternoon on $\mathrm{d} 10$ of the experiment. The cause of death is unknown, but was not suspected to be directly associated with the dietary treatment. The second calf was fed the SC treatment and developed a hernia on d 11 of the experiment. Severe discomfort was observed and the calf was euthanized on $\mathrm{d} 12$.

\section{Performance}

Although we found no differences in BW either at the beginning or end of the study among treatments, we did note a treatment $\times$ time interaction in calf starter intake (Table 2; Figures 1). The SC+XPC calves consumed more calf starter during wk 4 and 5 of the study, whereas calves fed SC also had increased calf starter intake during wk 5. Average daily gain was not different among treatments $(P \geq 0.161)$. Further, we found no treatment difference in the feed-to-gain ratio $(P \geq$ $0.221)$ or water intake $(P \geq 0.591)$.

Table 2. The effect of treatments on performance measurements in Holstein dairy calves from 1 to $35 \mathrm{~d}$ in age

\begin{tabular}{|c|c|c|c|c|c|c|c|}
\hline \multirow[b]{2}{*}{ Item } & \multicolumn{3}{|c|}{ Treatment $^{1}$} & \multirow{2}{*}{$\begin{array}{c}\text { Largest } \\
\text { SEM }\end{array}$} & \multicolumn{3}{|c|}{ Fixed effects, $P$-value } \\
\hline & Control & $\mathrm{SC}$ & $\mathrm{SC}+\mathrm{XPC}$ & & Treatment & Time & Treatment $\times$ time \\
\hline Initial BW, kg & 40.2 & 39.9 & 39.3 & 1.36 & $\leq 0.897$ & - & - \\
\hline Final BW, kg & 57.8 & 58.3 & 60.1 & 2.97 & $\leq 0.612$ & - & - \\
\hline Starter intake, $\mathrm{kg} / \mathrm{d}$ & $0.162^{\mathrm{a}}$ & $0.207^{\mathrm{ab}}$ & $0.237^{\mathrm{b}}$ & 0.0257 & $\leq 0.034$ & $\leq 0.0001$ & $\leq 0.021$ \\
\hline $\mathrm{ADG}, \mathrm{kg} / \mathrm{d}$ & 0.503 & 0.517 & 0.576 & 0.0812 & $\leq 0.161$ & $\leq 0.0001$ & $\leq 0.851$ \\
\hline Feed-to-gain ratio, $\mathrm{kg} / \mathrm{kg}$ & 1.89 & 1.85 & 1.66 & 0.251 & $\leq 0.221$ & $\leq 0.0001$ & $\leq 0.301$ \\
\hline Water intake, L/d & 1.65 & 1.77 & 1.93 & 0.313 & $\leq 0.591$ & $\leq 0.002$ & $\leq 0.994$ \\
\hline
\end{tabular}

${ }^{\mathrm{a}, \mathrm{b}}$ Differing superscripts within a row indicate a difference between means $(P<0.05)$.

${ }^{1}$ Treatments included a control group of calves that were fed a base milk replacer and calf starter; SC were fed the base milk replacer with $1 \mathrm{~g} / \mathrm{d}$ of SmartCare (Diamond V, Cedar Rapids, IA) and the base calf starter; and SC+XPC were fed the base milk replacer with 1 g/d of SmartCare and the base calf starter $+0.5 \%$ Original XPC (Diamond V). 


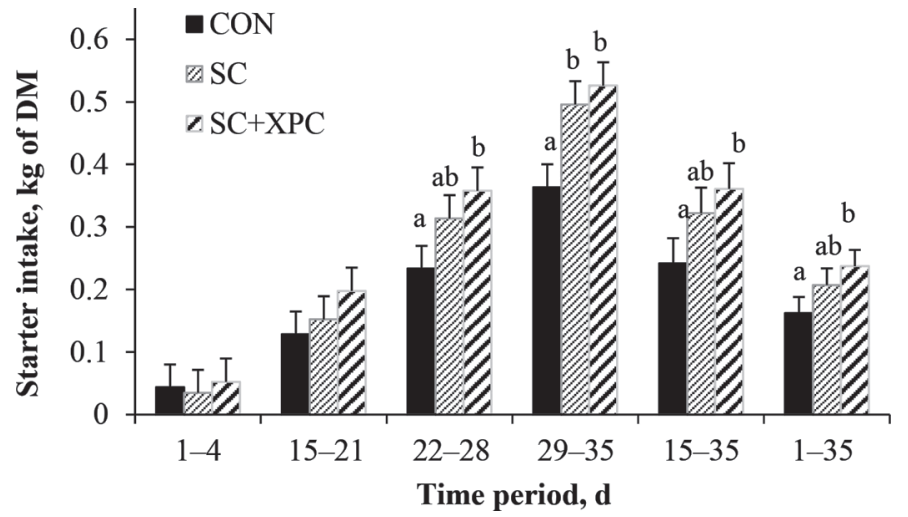

Figure 1. The effects of SmartCare (SC; Diamond V, Cedar Rapids, IA) in milk replacer and XPC (Diamond V) in a calf starter on calf starter intake in Holstein calves from 1 to $35 \mathrm{~d}$ in age. All calves were challenged with Salmonella enterica serotype Typhimurium strain SL1344 at a dose of 108 stationary-growth colony-forming units on $\mathrm{d}$ 14. Treatments included a control group $(\mathrm{CON})$ of calves that were fed a base milk replacer and calf starter; SC were fed the base milk replacer with $1 \mathrm{~g} / \mathrm{d}$ of SmartCare and the base calf starter; and $\mathrm{SC}+\mathrm{XPC}$ were fed the base milk replacer with $1 \mathrm{~g} / \mathrm{d}$ of SmartCare and the base calf starter $+0.5 \%$ XPC. Bars represent SEM. Differing letters $(\mathrm{a}, \mathrm{b})$ within a time period indicate a difference $(P<0.05)$. We noted a treatment $\times$ time interaction $(P=0.021)$.

\section{Hematology and Health}

The oral challenge with Salmonella enterica serotype Typhimurium strain SL1344 at a dose of 108 stationary-growth colony-forming units on d 14 after enrollment caused a mild systemic acute phase response, as evident by elevated rectal temperatures (Figure 2) and an increase in the ratio of neutrophils to lymphocytes in peripheral circulation. However, plasma haptoglobin concentrations did not increase following the Salmonella enterica challenge (Table 3 ).

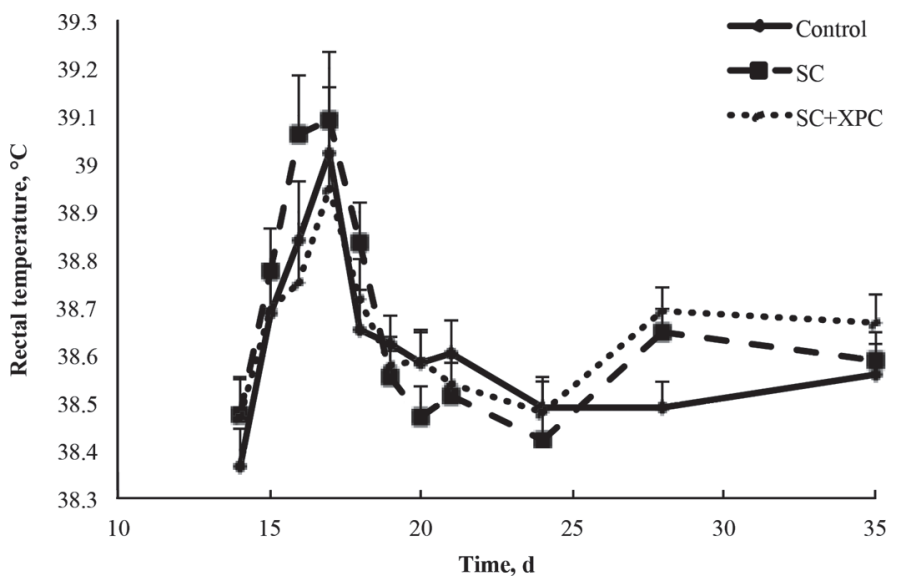

Figure 2. The effects of SmartCare (SC; Diamond V, Cedar Rapids, IA) in milk replacer and XPC (Diamond V) in a calf starter on rectal temperatures in Holstein calves after they were challenged with Salmonella enterica serotype Typhimurium strain SL1344 at a dose of 108 stationary-growth colony-forming units on d 14. Treatments included a control group of calves that were fed a base milk replacer and calf starter; SC were fed the base milk replacer with $1 \mathrm{~g} / \mathrm{d}$ of SmartCare and the base calf starter; and SC+XPC were fed the base milk replacer with $1 \mathrm{~g} / \mathrm{d}$ of SmartCare and the base calf starter + $0.5 \%$ XPC. Bars represent SEM. We found no treatment $\times$ time interaction $(P=0.396)$ or overall treatment differences $(P \geq 0.450)$.

We noted no treatment $\times$ time or treatment differences in either rectal temperature or plasma haptoglobin concentrations following the Salmonella enterica challenge (Figure 2; Table 3). No differences in the distribution of calves with different fecal scores were observed among treatments during the first $2 \mathrm{wk}$, but there were tendencies $(P \leq 0.085)$ for treatment differences during wk 3 and 5 of the study (Figure 3). During the third week, a greater proportion of control calves tended $(P=0.083)$ to have scours (fecal score 4$)$

Table 3. Effects of treatment on hematology and haptoglobin measurements in Holstein dairy calves from 1 to $35 \mathrm{~d}$ in age

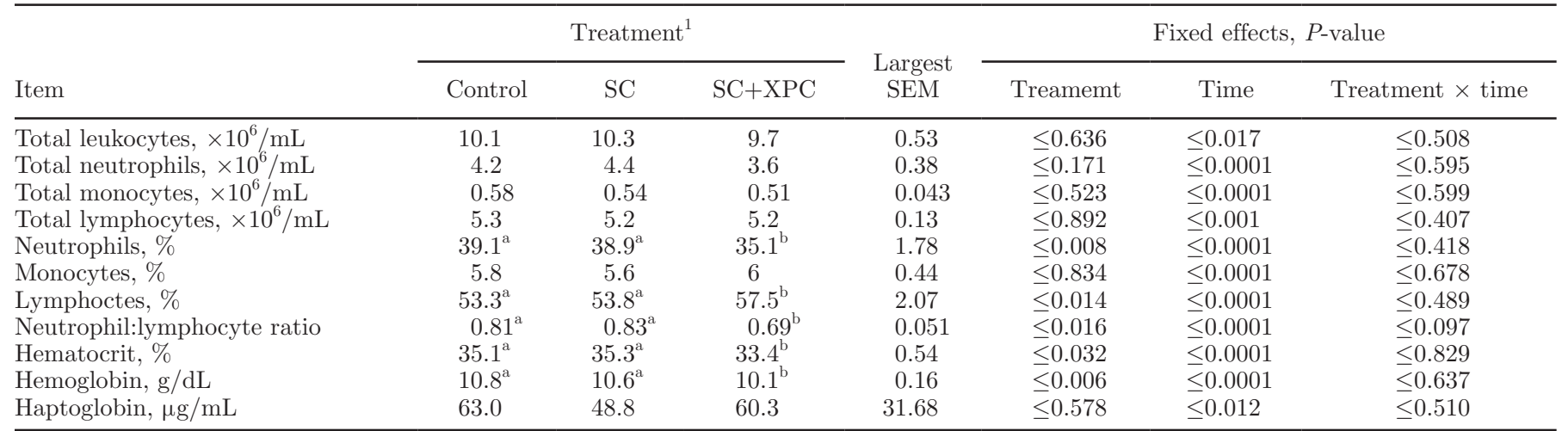

\footnotetext{
${ }^{\mathrm{a}, \mathrm{b}}$ Differing superscripts within a row indicate a difference between means $(P<0.05)$.
}

${ }^{1}$ Treatments included a control group of calves that were fed a base milk replacer and calf starter; SC were fed the base milk replacer with 1 $\mathrm{g} / \mathrm{d}$ of SmartCare (SC; Diamond V, Cedar Rapids, IA) and the base calf starter; and SC+XPC were fed the base milk replacer with $1 \mathrm{~g} / \mathrm{d}$ of SmartCare and the base calf starter $+0.5 \%$ Original XPC (Diamond V). 


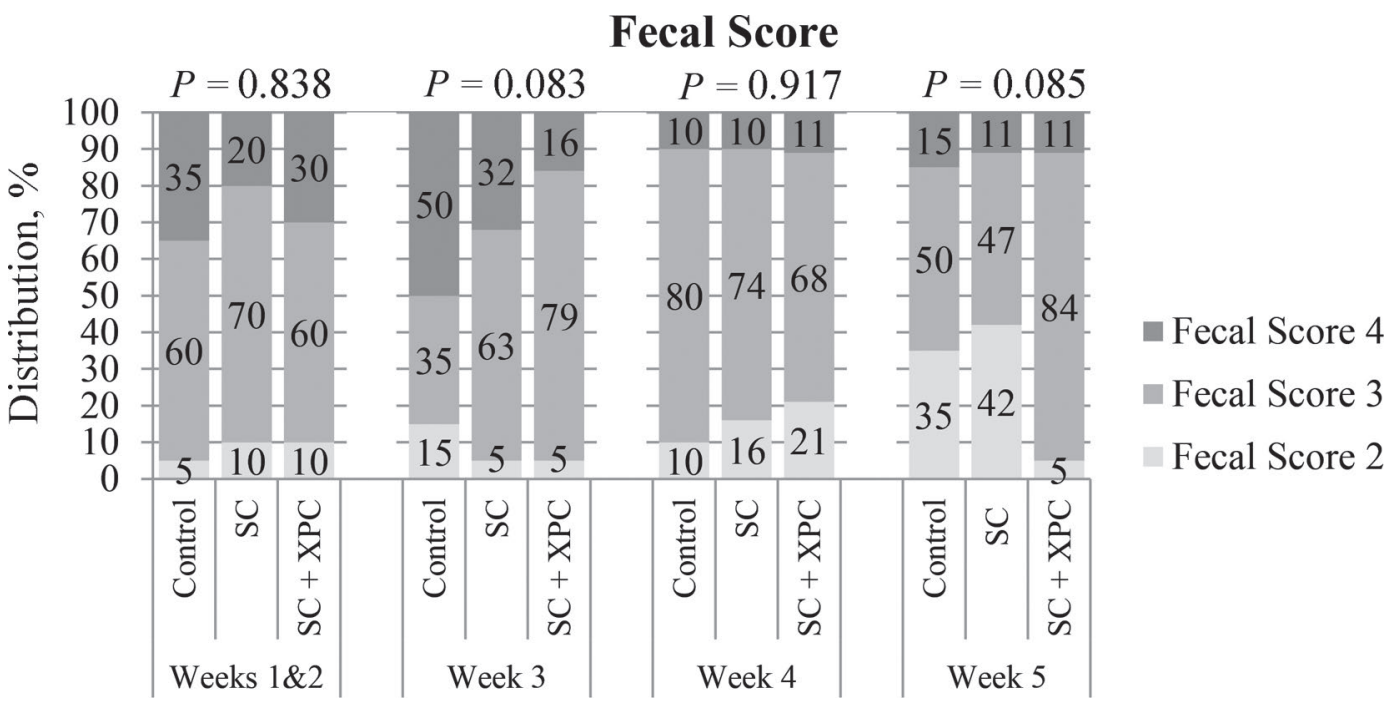

Figure 3. The effects of SmartCare (SC; Diamond V, Cedar Rapids, IA) in milk replacer and XPC (Diamond V) in a calf starter on the distributions of calves with a given fecal score. Calves were challenged with Salmonella enterica serotype Typhimurium strain SL1344 at a dose of 108 stationary-growth colony-forming units on d 14 . Fecal scores include $2=$ soft, pudding-like; $3=$ runny, pancake batter like; $4=$ watery, pulpy orange juice. Treatments included a control group of calves that were fed a base milk replacer and calf starter; SC were fed the base milk replacer with $1 \mathrm{~g} / \mathrm{d}$ of SmartCare and the base calf starter; and SC+XPC were fed the base milk replacer with $1 \mathrm{~g} / \mathrm{d}$ of SmartCare and the base calf starter $+0.5 \%$ XPC. Analysis was performed using a Chi-squared test in the Freq procedure in SAS (ver. 9.2, SAS Institute Inc., Cary, NC). Statistical significance is reported above each time period.

than either the SC or SC+XPC calves. During the fifth week, the calves fed the $\mathrm{SC}+\mathrm{XPC}$ treatment tended $(P$ $=0.085)$ to have a greater proportion of calves that had a fecal score of 3 .

We observed differences among treatments in the total peripheral blood counts of leukocytes, neutrophils, monocytes, or lymphocytes (Table 3); however, the $\mathrm{SC}+\mathrm{XPC}$ calves had a lower percentage of neutrophils and greater percentage of lymphocytes in circulation. There was a tendency for a treatment $\times$ time interaction $(P=0.097)$ on the neutrophil-to-lymphocyte ratio in peripheral circulation (Figure 4). Hematocrit and hemoglobin concentrations were both lower among the $\mathrm{SC}+\mathrm{XPC}$ calves compared with control and SC calves $(P \leq 0.032$; Table 3$)$.

\section{Salmonella Fecal Shedding and Colonization}

The Salmonella enterica strain was shed in feces from all calves at $1 \mathrm{~d}$ after the challenge and persisted among some calves up until $6 \mathrm{~d}$ after the challenge, when no more calves were shedding Salmonella in feces (Figure $5)$. We noted no treatment differences $(P \geq 0.115)$ in either the median number of days shedding the Salmonella or the area under the curve in $\log 10$ colonyforming units per gram of fecal material. No calves had Salmonella present in ileal fluid when calves were euthanized $21 \mathrm{~d}$ after the challenge. A tendency for a treatment difference was observed in the proportion of

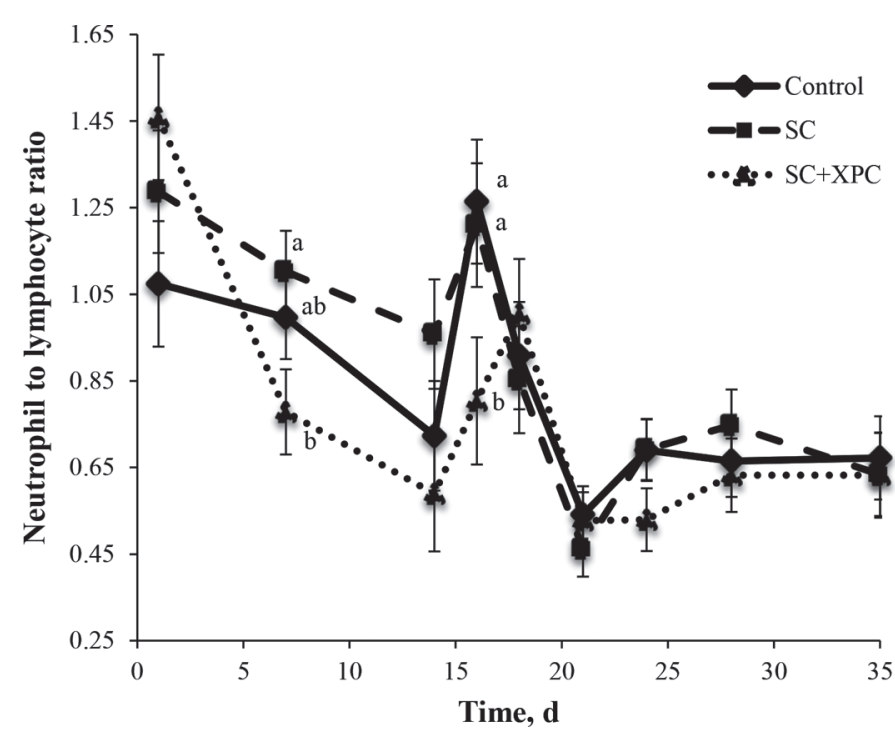

Figure 4. The effects of SmartCare (SC; Diamond V, Cedar Rapids, IA) in milk replacer and XPC (Diamond V) in a calf starter on neutrophil to lymphocyte ratios in peripheral circulation in Holstein calves. All calves were challenged with Salmonella enterica serotype Typhimurium strain SL1344 at a dose of 108 stationary-growth colonyforming units on $\mathrm{d}$ 14. Treatments included a control group of calves that were fed a base milk replacer and calf starter; SC were fed the base milk replacer with $1 \mathrm{~g} / \mathrm{d}$ of SmartCare and the base calf starter; and SC+XPC were fed the base milk replacer with $1 \mathrm{~g} / \mathrm{d}$ of SmartCare and the base calf starter $+0.5 \%$ XPC. Bars represent SEM. Differing letters $(\mathrm{a}, \mathrm{b})$ within a time period indicate a difference $(P<0.05)$. We observed a tendency $(P=0.097)$ for a treatment $\times$ time interaction. 
Table 4. Effect of treatment on Salmonella Typhimurium shedding in Holstein dairy calves from 1 to $35 \mathrm{~d}$ in age

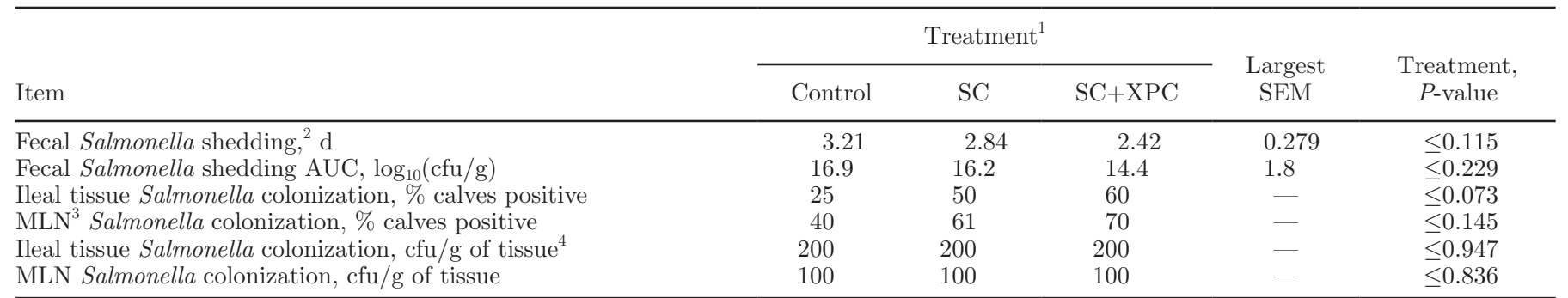

${ }^{1}$ Treatments included a control group of calves that were fed a base diet of milk replacer and calf starter; SC were fed a base diet of milk replacer and calf starter plus SmartCare (Diamond V, Cedar Rapids, IA) included in the milk replacer at a rate of $1 \mathrm{~g} /$ head per day; SC+XPC were fed a base diet of milk replacer and calf starter with SmartCare included in the milk replacer at a rate of $1 \mathrm{~g} /$ head per day and XPC (Diamond V) included at $0.5 \%$ of the calf starter.

${ }^{2}$ Significance reported from the Proc LifeTest (SAS ver. 9.2, SAS Institute Inc., Cary, NC): Wilcoxon-rank sum test.

${ }^{3} \mathrm{MLN}=$ mesenteric lymph node.

${ }^{4}$ Data are reported as the median cfu/g of tissue from Salmonella-positive calves only. Data were analyzed as the log base 10 (cfu/g).

calves that were positive for Salmonella enterica in ileal tissue at the end of the study (Table 4), but no difference $(P=0.145)$ was found in the proportion of calves that had Salmonella present in the MLN. Additionally, there were no differences $(P \geq 0.836)$ among treatments in the number of colony-forming units per gram of tissue from Salmonella-positive calves only (Table 4).

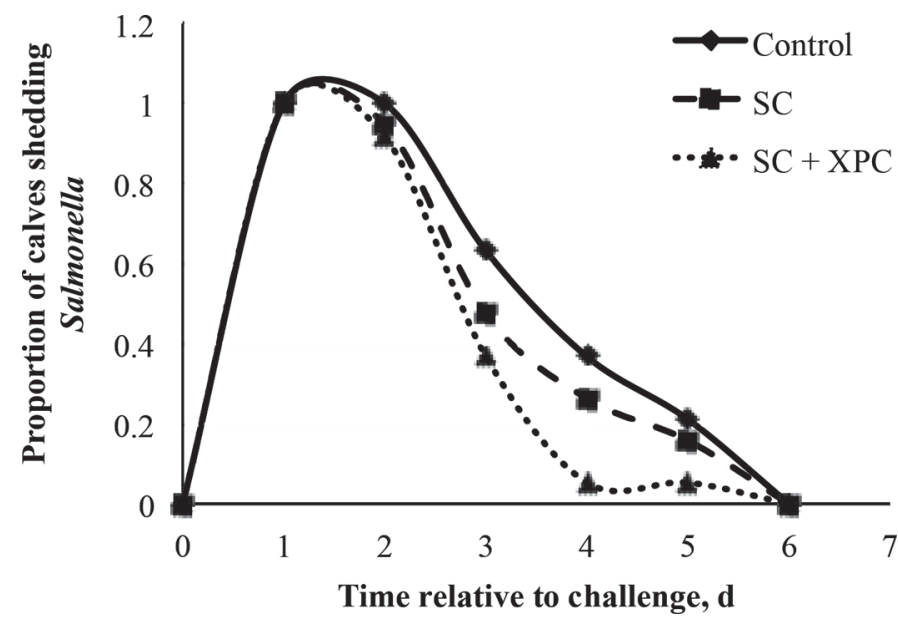

Figure 5. The effects of SmartCare (SC; Diamond V, Cedar Rapids, IA) in milk replacer and XPC in a calf starter on the proportion of calves shedding Salmonella in feces in Holstein calves. All calves were challenged with Salmonella enterica serotype Typhimurium strain SL1344 at a dose of 108 stationary-growth colony-forming units on d 14. Treatments included a control group of calves that were fed a base milk replacer and calf starter; SC were fed the base milk replacer with $1 \mathrm{~g} / \mathrm{d}$ of SmartCare and the base calf starter; and SC+XPC were fed the base milk replacer with $1 \mathrm{~g} / \mathrm{d}$ of SmartCare and the base calf starter $+0.5 \%$ XPC. Bars represent SEM. Data were analyzed using the Proc LifeTest (SAS ver. 9.2, SAS Institute Inc., Cary, NC). We found no treatment difference $(P=0.115)$ in the median number of days calves shed the Salmonella in feces.

\section{Organ Weights and Histology}

We found no differences among treatments $(P \geq$ 0.119 ) in organ weights at the time of harvest (Table $5)$. Additionally, no treatment differences $(P \geq 0.115)$ were noted in rumen or duodenum histology (Table 6). There was a tendency $(P=0.087)$ for a treatment difference in villi length in the ileum and a difference $(P=$ 0.018) in crypt depth in the ileum, whereas SC+XPC had greater depth (Table 7). Last, we observed no differences $(P \geq 0.536)$ in cellular infiltrate scoring in the ileum (Table 8$)$.

\section{DISCUSSION}

Both SC and XPC are Saccharomyces cerevisiae fermentation products used in the livestock industry. The $\mathrm{XPC}$ is a product containing yeast-derived metabolites that is supplemented to calves in calf starter and to heifers and cows in TMR. The SC product reportedly contains similar metabolites found in XPC as well as other metabolites, including those with enhanced antioxidant capacity. Unlike XPC, SC is water-dispersible and can be more easily supplemented to calves in their milk or milk replacer.

Similar to the current study, Brewer et al. (2014) conducted a study that provided SC in milk replacer and $3.5 \mathrm{~g}$ of XPC in an oral bolus, each day, to preweaned Holstein calves before and after they were challenged with the same Salmonella enterica serotype Typhimurium strain SL1344 used in our study. Despite the similarities of using the same challenge microorganism, differences exists between the 2 studies. Brewer et al. (2014) had only 2 treatments (control and SC+XPC), provided the XPC treatment to calves via an oral bolus, had a mixture of heifers and bull calves, treated multiple calves with sulfamethazine before the bacterial 
Table 5. Effect of treatment on organ weights of Holstein dairy calves from 1 to $35 \mathrm{~d}$ in age

\begin{tabular}{|c|c|c|c|c|c|}
\hline \multirow[b]{2}{*}{ Item } & \multicolumn{3}{|c|}{ Treatment $^{1}$} & \multirow{2}{*}{$\begin{array}{c}\text { Largest } \\
\text { SEM }\end{array}$} & \multirow{2}{*}{$\begin{array}{c}\begin{array}{c}\text { Fixed effect, } \\
P \text {-value }\end{array} \\
\text { Treatment }\end{array}$} \\
\hline & Control & $\mathrm{SC}$ & $\mathrm{SC}+\mathrm{XPC}$ & & \\
\hline Reticulorumen, kg & 0.56 & 0.64 & 0.61 & 0.059 & $\leq 0.381$ \\
\hline Percent reticulorumen $^{3}$ & 51.8 & 56.8 & 54.4 & 0.367 & $\overline{<} 0.119$ \\
\hline Omasum, kg & 0.14 & 0.13 & 0.16 & 0.024 & $\leq 0.651$ \\
\hline Percent omasum ${ }^{3}$ & 13.5 & 11.9 & 14.3 & 0.020 & $\leq 0.493$ \\
\hline Abomasum, kg & 0.36 & 0.35 & 0.32 & 0.017 & $\leq 0.211$ \\
\hline Percent abomasum ${ }^{2}$ & 34.7 & 31.3 & 31.2 & 0.210 & $\leq 0.134$ \\
\hline Total intestines, kg & 3.50 & 3.56 & 3.36 & 0.277 & $\leq 0.772$ \\
\hline Liver, kg & 1.07 & 1.12 & 1.06 & 0.089 & $\leq 0.402$ \\
\hline Spleen, kg & 0.16 & 0.17 & 0.17 & 0.007 & $\leq 0.776$ \\
\hline Kidney, $\mathrm{kg}$ & 0.43 & 0.46 & 0.37 & 0.035 & $\leq 0.205$ \\
\hline
\end{tabular}

${ }^{1}$ Treatments included a control group of calves that were fed a base milk replacer and calf starter; SC were fed the base milk replacer with $1 \mathrm{~g} / \mathrm{d}$ of SmartCare (Diamond V, Cedar Rapids, IA) and the base calf starter; and $\mathrm{SC}+\mathrm{XPC}$ were fed the base milk replacer with $1 \mathrm{~g} / \mathrm{d}$ of SmartCare and the base calf starter $+0.5 \%$ Original XPC (Diamond V).

${ }^{2}$ Percent weight of each measured compartment of the foregut.

challenge, and inoculated the calves with Salmonella enterica using an oral gel capsule. In the present study, $\mathrm{SC}$ was fed to calves separately in addition to having a $\mathrm{SC}+\mathrm{XPC}$ treatment, XPC was fed to calves in the calf starter at a fixed percentage of the DM, and calves in the current study would have to consume $700 \mathrm{~g}$ of calf starter $\mathrm{DM} / \mathrm{d}$ to consume the $3.5 \mathrm{~g}$ of XPC given in the bolus in Brewer et al. (2014). Additionally, the present study only used bull calves, did not treat any calves with antibiotics, and were inoculated by adding the Salmonella enterica directly to their morning milk replacer along with the addition of sodium bicarbonate and calcium carbonate to act as a buffer. Calves in the $\mathrm{SC}+\mathrm{XPC}$ at the time of the Salmonella enterica chal- lenge were consuming approximately $0.55 \mathrm{~g}$ of XPC/d compared with the $3.5 \mathrm{~g}$ in the study by Brewer et al. (2014).

Saccharomyces cerevisiae fermentation products may improve the performance of livestock. Both nonruminants and ruminants reported increased DMI, nutrient digestibility, ADG, gain-to-feed ratio, and overall weight gain (Haddad and Goussous, 2005; Gao et al., 2008). In the present study, dairy calves supplemented with XPC in the calf starter had increased starter intake during the fourth and fifth week of the study when compared with the control calves. Brewer et al. (2014) did not record calf starter intake, ADG, or efficiency, but their data indicated that calves fed $\mathrm{SC}+\mathrm{XPC}$ had

Table 6. Effects of treatment on rumen and duodenum histology in 35-d-old Holstein dairy calves

\begin{tabular}{|c|c|c|c|c|c|}
\hline \multirow[b]{2}{*}{ Item } & \multicolumn{3}{|c|}{ Treatment $^{1}$} & \multirow{2}{*}{$\begin{array}{c}\text { Largest } \\
\text { SEM }\end{array}$} & \multirow{2}{*}{$\begin{array}{c}\begin{array}{c}\text { Fixed effect, } \\
P \text {-value }\end{array} \\
\text { Treatment }\end{array}$} \\
\hline & Control & $\mathrm{SC}$ & $\mathrm{SC}+\mathrm{XPC}$ & & \\
\hline \multicolumn{6}{|l|}{ Rumen } \\
\hline Papillae length, $\mu \mathrm{m}$ & 1,001 & 1,181 & 1,128 & 92.6 & $\leq 0.367$ \\
\hline Papillae width, $\mu \mathrm{m}$ & 367 & 354 & 392 & 20.1 & $\leq 0.295$ \\
\hline Papillae density, ${ }^{2} \mu \mathrm{m}$ & 1,682 & 1,694 & 1,859 & 127.8 & $\leq 0.544$ \\
\hline Rumen wall thickness, ${ }^{3} \mu \mathrm{m}$ & 2,649 & 2,540 & 2,687 & 213.6 & $\leq 0.875$ \\
\hline \multicolumn{6}{|l|}{ Duodenum } \\
\hline Villi length, $\mu \mathrm{m}$ & 251 & 266 & 273 & 15.6 & $\leq 0.551$ \\
\hline Villi width, $\mu \mathrm{m}$ & 109 & 120 & 122 & 6.5 & $\leq 0.326$ \\
\hline Villi density, ${ }^{2} \mu \mathrm{m}$ & 753 & 762 & 765 & 36.5 & $\overline{<} 0.938$ \\
\hline Crypt depth, $\mu \mathrm{m}$ & 475 & 425 & 453 & 23.1 & $\leq 0.294$ \\
\hline Crypt width, $\mu \mathrm{m}$ & 57 & 55 & 66 & 4 & $\leq 0.115$ \\
\hline
\end{tabular}

${ }^{1}$ Treatments included a control group of calves that were fed a base milk replacer and calf starter; SC were fed the base milk replacer with $1 \mathrm{~g} / \mathrm{d}$ of SmartCare (Diamond V, Cedar Rapids, IA) and the base calf starter; and $\mathrm{SC}+\mathrm{XPC}$ were fed the base milk replacer with $1 \mathrm{~g} / \mathrm{d}$ of SmartCare and the base calf starter $+0.5 \%$ Original XPC (Diamond V).

${ }^{2}$ Density is the distance between 5 papillae.

${ }^{3}$ Rumen wall thickness is the distance from the epithelium through muscle. 
Table 7. Effects of treatment on ileum histology in 35-d-old Holstein dairy calves

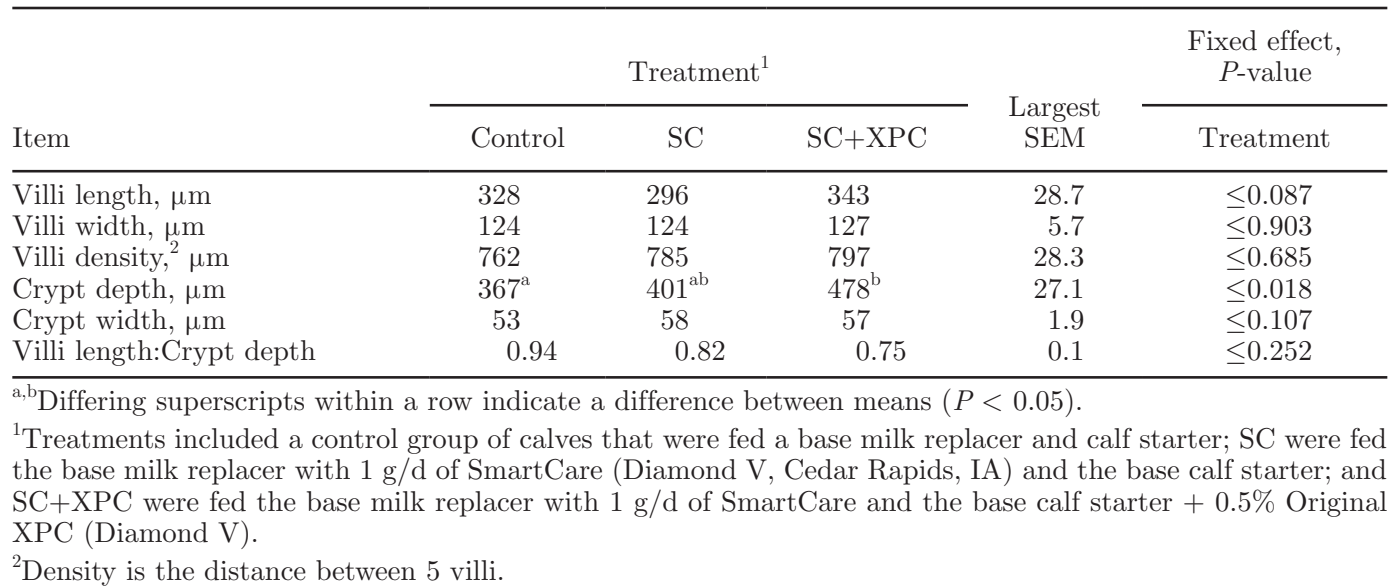

a greater BW gain on a percentage basis over the study period when compared with the control calves. Supporting the increase in calf starter intake observed in the present study, Lesmeister et al. (2004) found that a less concentrated form of Saccharomyces cerevisiae fermentation product, known as Original XP (XP), increased final BW, ADG, and starter consumption. Magalhães et al. (2008) fed XP to 255 preweaned dairy calves at $2 \%$ of calf starter DM. Although they did not observe an improvement in either calf starter intake or BW gain, there was a significant reduction in mortality rate of calves fed XP (7.5 vs. 12.1\%).

Hematocrit levels were greater in the control and SC calves compared to the $\mathrm{SC}+\mathrm{XPC}$ calves throughout the entire experiment. Lesmeister et al. (2004) reported that calves fed XP had lower hematocrit percentages

Table 8. Effects of treatment on ileum cells in 35-d-old Holstein dairy calves

\begin{tabular}{|c|c|c|c|c|}
\hline \multirow[b]{2}{*}{ Item } & \multicolumn{3}{|c|}{ Treatment $^{1}$} & \multirow{2}{*}{$\begin{array}{c}\begin{array}{c}\text { Fixed effect } \\
P \text {-value }\end{array} \\
\text { Treatment }\end{array}$} \\
\hline & Control & $\mathrm{SC}$ & $\mathrm{SC}+\mathrm{XPC}$ & \\
\hline Lymphocytes, ${ }^{2}$ no. & 20 & 19 & 19 & $<0.536$ \\
\hline Score $1, \%$ & 0.15 & 0.21 & 0.37 & - \\
\hline Score $2, \%$ & 0.75 & 0.63 & 0.53 & - \\
\hline Score $3, \%$ & 0.10 & 0.16 & 0.11 & - \\
\hline Eosinophil, ${ }^{3}$ no. & 20 & 19 & 19 & $\leq 0.723$ \\
\hline Score 1, \% & 0.45 & 0.58 & 0.58 & - \\
\hline Score $2, \%$ & 0.40 & 0.37 & 0.26 & - \\
\hline Score 3, \% & 0.15 & 0.05 & 0.16 & - \\
\hline Crypt goblets, ${ }^{4}$ no. & 20 & 19 & 19 & $\leq 0.818$ \\
\hline Score $1, \%$ & 0.45 & 0.42 & 0.42 & - \\
\hline Score $2, \%$ & 0.45 & 0.42 & 0.53 & - \\
\hline Score $3, \%$ & 0.10 & 0.16 & 0.05 & - \\
\hline Villus goblets, ${ }^{5}$ no. & 20 & 19 & 19 & $\leq 0.777$ \\
\hline Score $1, \%$ & 0.80 & 0.68 & 0.79 & - \\
\hline Score $2, \%$ & 0.20 & 0.26 & 0.16 & - \\
\hline Score 3, \% & 0.00 & 0.05 & 0.05 & - \\
\hline
\end{tabular}

${ }^{1}$ Treatments included a control group that were fed a base milk replacer and calf starter; SC were fed the base milk replacer with $1 \mathrm{~g} / \mathrm{d}$ of SmartCare (SC; Diamond V, Cedar Rapids, IA) and the base calf starter; and $\mathrm{SC}+\mathrm{XPC}$ were fed the base milk replacer with $1 \mathrm{~g} / \mathrm{d}$ of SmartCare and the base calf starter $+0.5 \%$ Original XPC (Diamond V).

${ }^{2}$ Lymphocytes receive a 1 scoring if they were rare or not present, a 2 for intraepithelial or frequent occurrence, and a 3 for exudative occurrence.

${ }^{3}$ Eosinophils receive a 1 scoring if they were rare or not present, a 2 for intraepithelial or frequent occurrence, and a 3 for exudative occurrence.

${ }^{4}$ Crypt goblets hyperplasia were scored a 1 for normal, a 2 for mild or moderate increase in size and mitoses, and a 3 for marked increase in size and mitoses.

${ }^{5}$ Villus goblets cell mass were scored a 1 for normal mass, a 2 for mild to moderate increases in mass, and a 3 for marked increase in mass. 
than calves on the other treatments. The SC+XPC calves tended to have less loose fecal scores than the control calves immediately after the challenge. Brewer et al. (2014) also reported that diarrhea scores were reduced in calves fed $\mathrm{SC}+\mathrm{XPC}$ than controls after the Salmonella enterica challenge. In agreement, although Magalhães et al. (2008) did not experimentally challenge their calves, that group noted that fecal scores and diarrhea incidences were reduced in calves fed XP. However, the difference in hematocrit in the present study likely cannot be completely explained by differences in fecal scores or incidences of diarrhea, because the differences in hematocrit were observed over the course of the entire study.

The Salmonella enterica challenge caused similar increases in rectal temperature among all treatments, which returned to baseline temperatures within $6 \mathrm{~d}$ post-challenge. These data are in contrast to those of Brewer et al. (2014), who found that SC+XPC calves had reduced rectal temperature compared with control calves from 1 to $6 \mathrm{~d}$ postchallenge. Although the present study did not report treatment differences in rectal temperatures after the Salmonella enterica challenge, other variables may indicate that the calves fed $\mathrm{SC}+\mathrm{XPC}$ had attenuated or delayed responses. Calves supplemented with SC+XPC had reduced neutrophilto-lymphocyte ratios immediately after the Salmonella enterica challenge, and did not peak as high as the other 2 treatments. The peak in the neutrophil-tolymphocyte ratio among SC+XPC calves occurred on d 18, whereas the peak among the control and SC calves occurred more rapidly on d 16. Additionally, if the data are evaluated as the relative increase from immediately before the challenge to peak all treatments had similar increases after the challenge. The biological significance of the delayed increase in the neutrophil-tolymphocyte ratio needs further investigation because a delay in the activation of neutrophils after an infection can be viewed as a negative response. Alternatively, a delayed or attenuated response may also indicate that response was not needed to the same degree as calves on other treatments because the infection was better controlled locally or by some other component of the immune system. Lastly, it should be noted that none of the treatment groups had elevated plasma haptoglobin concentrations following the Salmonella enterica challenge. This suggests that the Salmonella enterica challenge in these calves was mild. In fact, none of the 78 calves that were challenged died or needed any antimicrobial or anti-inflammatory interventions following the Salmonella enterica challenge.

Neither the median days that calves shed the challenge Salmonella enterica nor the area under the curve of colony-forming units per gram of fecal material were different in the present study. In contrast, Brewer et al. (2014) reported that SC+XPC treatment had a reduced percentage of calves shedding the Salmonella enterica than the control calves. However, in the present study, the percentage of $\mathrm{SC}$ and $\mathrm{SC}+\mathrm{XPC}$ calves positive for ileal colonization of the Salmonella enterica was greater than that of the control calves. In contrast, Brewer et al. (2014) reported less Salmonella enterica colonization in the ileum of SC+XPC-supplemented calves than control calves. There was a difference between the present study and the study conducted by Brewer et al. (2014) in the total counts of Salmonella enterica; Brewer et al. (2014) reported approximately $10^{3}$ to $10^{4} \mathrm{cfu} / \mathrm{g}$ of ileal tissue whereas the present study recorded $10^{1}$ to $10^{2} \mathrm{cfu} / \mathrm{g}$ of ileal tissue and MLN upon direct plating.

In the present study, no treatment differences were observed in ruminal or duodenal weights or histology. In contrast, Brewer et al. (2014) reported that rumen papillae width increased with $\mathrm{SC}+\mathrm{XPC}$. The $\mathrm{SC}+\mathrm{XPC}$ calves had increased crypt depth in the ileum in the current study. van Beers-Schreurs et al. (1998) reported that crypt depth and width increased in pigs fed weanling diets when compared with pigs only consuming milk. van Beers-Schreurs et al. (1998) concluded that increased nutrients in the gastrointestinal tract promoted greater crypt hyperplasia, which could be explained, at least partially, by the greater calf starter intake among those calves in the last 2 wk of the study.

\section{CONCLUSIONS}

Preweaned dairy calves that were fed $1 \mathrm{~g} / \mathrm{d}$ of SmartCare in milk replacer and $0.5 \%$ XPC in calf starter had improved calf starter intake compared with a negative control. Some of the improvements in calf starter intake could be attributed to the SmartCare in milk replacer alone, but the data indicate that greater benefits were observed when the SmartCare in the milk replacer and $\mathrm{XPC}$ in the calf starter were fed together.

\section{ACKNOWLEDGMENTS}

The research was financially supported by Diamond V Mills Inc., Cedar Rapids, Iowa. The authors thank Jeff Dailey with USDA-ARS Livestock Issues Research Unit for his help collecting the data.

\section{REFERENCES}

Brewer, M. T., K. L. Anderson, I. Yoon, M. F. Scott, and S. A. Carlson. 2014. Amelioration of salmonellosis in pre-weaned dairy calves 
fed Saccharomyces cerevisiae fermentation products in feed and milk replacer. Vet. Microbiol. 172:248-255.

Gao, J., H. J. Zhang, S. H. Yu, S. G. Wu, I. Yoon, J. Quigley, Y. P. Gao, and G. H. Qi. 2008. Effects of yeast culture in broiler diets on performance and immunomodulatory functions. Poult. Sci. 87:1377-1384.

Haddad, S. G., and S. N. Goussous. 2005. Effect of yeast culture supplementation on nutrient intake, digestibility and growth performance of Awassi lambs. Anim. Feed Sci. Technol. 118:343-348.

Jensen, G. S., K. M. Patterson, and I. Yoon. 2008. Yeast culture has anti-inflammatory effects and specifically activates NK cells. Comp. Immunol. Microbiol. Infect. Dis. 31:487-500.

Lesmeister, K. E., A. J. Heinrichs, and M. T. Gabler. 2004. Effects of supplemental yeast (Saccharomyces cerevisiae) culture on rumen development, growth characteristics, and blood parameters in neonatal dairy calves. J. Dairy Sci. 87:1832-1839.

Magalhães, V. J., F. Susca, F. S. Lima, A. F. Branco, I. Yoon, and J. E. Santos. 2008. Effect of feeding yeast culture on performance, health, and immunocompetence of dairy calves. J. Dairy Sci. 91:1497-1509.

Makimura, S., and N. Suzuki. 1982. Quantitative determination of bovine serum haptoglobin and its elevation in some inflammatory diseases. Nihon Juigaku Zasshi 44:15-21.

NAHMS. 2002. Dairy Health and Management. USDA:APHIS:VS, Fort Collins, CO

NAHMS. 2007. Part1: Reference of Dairy Cattle Health and Management Practices in the United States. USDA:APHIS:VS, Fort Collins, CO.

van Beers-Schreurs, H. M., M. J. Nabuurs, L. Vellenga, H. J. Kalsbeek-van der Valk, T. Wensing, and H. J. Breukink. 1998. Weaning and the weanling diet influence the villous height and crypt depth in the small intestine of pigs and alter the concentrations of short-chain fatty acids in the large intestine and blood. J. Nutr. 128:947-953. 